\title{
Comparison of Total Phenolic Content, Total Flavonoid Content, Antioxidant capacity and Free Radical Scavenging Activity of Leaves of Elaeocarpus sphaericus and Roots of Pelargonium zonale
}

\author{
Ravi Deepika*, Jagtar Singh and Naindeep Kaur \\ Department of Biotechnology, Panjab University, Chandigarh, India \\ *Corresponding author
}

\begin{tabular}{l} 
K e y w o r d s \\
$\begin{array}{l}\text { Elaeocarpus sphaericus, } \\
\text { Pelargonium zoanle, } \\
\text { Antioxidants, Total phenolic } \\
\text { content (TPC), Total } \\
\text { flavonoid content (TFC), } \\
\text { Total antioxidant capacity } \\
\text { (TAC) and free radicals }\end{array}$ \\
\hline Article Info \\
$\begin{array}{l}\text { Accepted: } \\
\text { 24 January } 2018 \\
\text { Available Online: } \\
\text { 10 February } 2018\end{array}$ \\
\hline
\end{tabular}

A B S T R A C T
Elaeocarpus sphaericus is commonly known as Rudraksha belonging to family Elaeocarpaceae and Pelargonium zoanle is a perennial small shrub, belonging to family Geraniaceae are one of the oldest and popular medicinal plants, rich in antioxidants and phytonutrients. In this study, Methanolic leaf extract of E. sphaericus and root extract $P$. zoanle were prepared for the comparative determination of total phenolic content, total flavonoid content, total antioxidant capacity and free radical scavenging activity by using Folin-Ciocalteau method, aluminium chloride colorimetric method, phosphomolybdenum method, DPPH and ABTS assay respectively. According to results, TPC and TFC was higher in leaf extract of E. sphaericus with the value of $37.5 \mathrm{mg} \mathrm{GAE} / \mathrm{g}$ of DW(dry weight) and $53.3 \mathrm{mg} \mathrm{QE} / \mathrm{g}$ of DW of extract as compare to P.zoanle (TPC: $24 \mathrm{mg}$ GAE/g of DW and TFC: $21.05 \mathrm{QE} / \mathrm{g}$ of DW of extract). TAC of root extract of P.zoanle (25mg AAE/g of DW) was higher than leaf extract of E. sphaericus (14.28mg AAE/g of DW). In DPPH assay, \% inhibition was higher in E. sphaericus with $\mathrm{IC}_{50}$ value of $477.125 \mu \mathrm{g} / \mathrm{ml}$ in comparison to $P$. zoanle with $\mathrm{IC}_{50}$ value of $659.89 \mu \mathrm{g} / \mathrm{ml}$. ABTS assay showed that the free radical scavenging activity of both $E$. sphaericus $\left(\mathrm{IC}_{50}\right.$ value $\left.=2.96 \mu \mathrm{g} / \mathrm{ml}\right)$ and $P$. zoanle $\left(\mathrm{IC}_{50}\right.$ value $\left.=2.96 \mu \mathrm{g} / \mathrm{ml}\right)$ was lower than the synthetic antioxidant $\mathrm{BHT}\left(\mathrm{IC}_{50}\right.$ value $=$ $12.56 \mu \mathrm{g} / \mathrm{ml}$ ). It was observed that both medicinal plants can be used in pharmaceutical and food industry in order to replace synthetic antioxidants with natural antioxidants.

\section{Introduction}

It has been established that antioxidants play a vital role in preventing the oxidative stress and also certain degenerative diseases including atherosclerosis, heart diseases, ageing, diabetes mellitus, cancer, immunesuppression, neurodegenerative diseases and others (Bhatt et al., 2013). The relationship between free radicals production and disease occurrence can be best explained by the oxidative stress (Sies, 1996). Oxidative stress signifies the imbalance between free radical production and antioxidant defense lead to high concentration of free radicals causes oxidation of biological molecules such as DNA, RNA, Proteins, carbohydrates and lipids (Betteridge, 2000). Free radicals are highly reactive chemical species (ROS and RNS) having unpaired electrons in their outer shells. Under physiologic and pathologic state, both ROS and RNS are generated in animals 
and human cells (Fang et al., 2002). Oxidation process induced by ROS known to be the main reason behind the tissue damage and death and various cardiovascular and neurodegenerative diseases (Battin et al., 2009). ROS are not only associated with tissue damage and diseases but also involved in lipid peroxidation causes food deterioration. It has been estimated that $70-80 \%$ of the world's population cannot afford modern medicine; use of medicinal plants can be an important source of natural antioxidants. Therefore, medicinal plants being viewed as potent source of antioxidants and used as an alternative source of medicine to combat the diseases associated with oxidative stress. Because these plants contain different chemical compounds such as phytochemicals, phenolic compounds, tannins, flavonoids and have pharmacological, antibacterial and antifungal properties that work as natural antibiotics (Roja and Rao, 2000 and Miguel et al., 2010).

Antioxidant defense mechanism is present in all, the aerobic organism including human beings help to cure diseases, improve health and protect against oxidative stress by eliminating and repairing damaged molecules (Yildirim et al., 2001). Antioxidant is a substance which causes scavenging of free radicals and their actions (Sies, 1996). There are many synthetic antioxidants i.e., butylated hydroxyl anisole (BHA) and butylated hydroxyl toluene (BHT) is available in food industry used to prevent unwanted deterioration of food products. Moreover, synthetic antioxidants possess moderate antioxidant activity, less solubility, high volatility, and instability at high temperature as compare to natural antioxidants (Barlow, 1990 and Branen, 1975). It has been reported that these synthetic antioxidants has adverse effects on human's health (Siddhuraju and Becker, 2003). So, recent research has been shifted towards, the use of naturally occurring antioxidants present in medicinal plants as therapeutics antioxidants.

In this study, we quantify antioxidants in medicinal plants selected from north Indian region i.e., methanolic leaf extract of $E$. sphaericus and roots of $P$. zonale for different properties like total phenolic content, total flavonoid content, antioxidant capacity and free radical scavenging activity. Roots of Pelargoinum species are used by people of South Africa for treatment of tuberculosis and coughs, as roots known to possess antibacterial, antifungal and anti-tubercular activity (Mativandlela et al., 2006). To the best of our knowledge, this is first study to check antioxidant properties on leaf extracts of $E$. sphaericus and roots of $P$. zoanle from north Indian region.

\section{Materials and Methods}

\section{Chemicals}

Chemicals used in this study included: - 2, 2diphenyl-1-picryhydrazyl (DPPH) and TROLOX from Sigma-Aldrich, St. Louis, USA. Butylated Hydroxy Toluene (BHT), Ascorbic Acid, Quercetin, EDTA, Folin Ciocalteau Reagent, sodium carbonate, potassium acetate, potassium persulphate, sulphuric acid, ammonium molybedate, ABTS and Gallic acid from Hi-media, Mumbai, India.

\section{Collection, drying and prepration of samples}

E. sphaericus and $P$. zoanle was obtained from Botanical garden, Panjab University, Chandigarh. Leaves from E. sphaericus and roots from $P$. zoanle were used for sample preparation. Leaves and roots were washed with water followed by drying at $37^{\circ} \mathrm{c}$ in incubator for 3-4 days, and then grounded into fine powder in electronic grinder. After this, 
powder of leaves and roots immersed in $100 \%$ methanol in 1:10 ratio. The mixture was kept in shaker at $37^{\circ} \mathrm{c}$ at $180 \mathrm{rpm}$ for 24 hours and filtered using whatman no. 1 paper. Then, this methanolic mixture was concentrated, dried and stored in methanol at $4{ }^{\circ} \mathrm{c}$ for further antioxidant analysis.

\section{Chemical analysis}

\section{Determination of total phenolic content (TPC)}

The total phenolic content was determined by using Folin-Ciocalteu method given by Demiray et al., 2009. Stock solution of $1 \mathrm{mg} / \mathrm{ml}$ was used to prepare different concentrations $(0.2$ to $18 \mu \mathrm{g} / \mathrm{ml})$ of $100 \mu \mathrm{l}$. To each concentration, 500 $\mu 1$ of Folin-Ciocalteu reagent (diluted 10 times with distilled water) and $400 \mu 1$ of sodium carbonate $(7.5 \% \mathrm{w} / \mathrm{v})$ was added to make volume of $1 \mathrm{ml}$. Thereafter, the mixture was vortexed and incubated in dark for 30 minutes at room temperature. Then absorbance was measured at $765 \mathrm{~nm}$ in double beam spectrophotometer. The TPCs of the sample extracts were expressed as gallic acid equivalents (GAE) in $\mathrm{mg}$ per $\mathrm{g}$ of dry weight of the extracts.

\section{Determination of total flavonoid content (TFC)}

Aluminium chloride (Chang et al., 2002) is a colorimetric method used to determine the flavonoid content of sample extracts. Different dilutions $(100$ to $8500 \mu \mathrm{g} / \mathrm{ml})$ of sample extracts were prepared from stock solutions of $10 \mathrm{mg} / \mathrm{ml}$. In $100 \mu 1$ of each dilution, $300 \mu \mathrm{l}$ of $100 \%$ methanol, $20 \mu \mathrm{l}$ of $10 \%$ aluminium chloride, $20 \mu \mathrm{l}$ of $1 \mathrm{M}$ Potassium acetate was added and $560 \mu 1$ of distilled water was added for volume make up of $1000 \mu 1$. Thereafter, the mixture was vortexed and incubated in dark for 30 minutes at room temperature. Then absorbance was measured at $420 \mathrm{~nm}$. The
TFCs of the sample extracts were expressed as Quercetin equivalents (QE) in mg per $g$ of dry weight of the extract.

\section{Determination of total antioxidant capacity}

Phosphomolybdenum assay (Prieto et al., 1999) was used to measure total antioxidant capacity of sample extracts in which ascorbic acid was used as a control. Stock of each sample $(10 \mathrm{mg} / \mathrm{ml})$ was used to prepare different concentrations $(20-1000 \mu \mathrm{g} / \mathrm{ml})$. To $500 \mu \mathrm{l}$ of each dilution, $1.5 \mathrm{ml}$ of TAC reagent $(10 \mathrm{ml}$ concentrated sulphuric acid $+1.005 \mathrm{~g}$ sodium dihydrogen monohydrate $+1.47 \mathrm{~g}$ ammonium molybdate, dissolved in $290 \mathrm{ml}$ of distilled water) was added. Thereafter, the mixture was kept in water bath at $95^{\circ} \mathrm{C}$ for 1 hour; the absorbance was measured at $695 \mathrm{~nm}$. The results were expressed as $\mu \mathrm{g}$ Ascorbic Acid Equivalent (AAE)/10 mg extract.

\section{Determination of free radical scavenging activity by DPPH assay}

The stable 1,1-diphenyl-2-picryl hydrazyl radical (DPPH) was used for determination of free radical-scavenging activity of the extracts (Surinrut et al., 2005). 500 $\mu 1$ of different concentrations of $(40-900 \mu \mathrm{g} / \mathrm{ml})$ each sample extract were added, to $500 \mu \mathrm{l}$ of $0.004 \%$ methanolic solution of DPPH and $500 \mu \mathrm{l}$ of $100 \%$ methanol. After $15 \mathrm{~min}$ at room temperature, the absorbance was recorded at $517 \mathrm{~nm}$. Negative control was prepared using $1000 \mu 1$ of methanol and 500 $\mu 1$ of DPPH. The experiment was repeated for three times. BHT and quercetin were used as standard controls. $\mathrm{IC}_{50}$ values denote the concentration of sample, which is required to scavenge $50 \%$ of DPPH free radicals. The free radical scavenging activity was calculated using following formula:-

Free radical scavenging activity $(\%)=\left[\left(\mathrm{A}_{0}-\right.\right.$ $\left.\left.\mathrm{A}_{\mathrm{S}}\right)\right] \times 100$ 
$\mathrm{A}_{0}=$ absorbance reading of negative control

$A_{S}=$ absorbance reading of sample extracts

\section{Determination of free radical scavenging} activity by ABTS assay

The total antioxidant activity of the samples was measured by [2, 2'-azino-bis (3ethylbenzthiazoline-6-sulphonic acid)] ABTS $\bullet+$ radical cation decolorization assay given by Re et al., (1999). Equal quantities of both, $7 \mathrm{mM} \mathrm{ABTS}+$ aqueous solution and $2.4 \mathrm{mM}$ potassium persulfate react in the dark for 12-16 hours at room temperature to produce ABTS $\bullet+$ solution. Before performing assay, ABTS•+ solution was diluted with methanol to obtain an absorbance of $0.700+0.01$ at $734 \mathrm{~nm}$. $500 \mu \mathrm{l}$ of ABTS•+ solution was added to $500 \mu \mathrm{l}$ different dilutions $(0.25-5.5 \mu \mathrm{g} / \mathrm{ml})$ of sample extracts. Then absorbance was measured after 7 minutes at $734 \mathrm{~nm}$. The free radical scavenging activity was calculated using following formula:-

Free radical scavenging activity $(\%)=\left[\left(\mathrm{A}_{0}\right.\right.$ $\left.\left.\mathrm{A}_{\mathrm{S}}\right)\right] \mathrm{x} 100$

$\mathrm{A}_{0}=$ absorbance reading of negative control $A_{S}=$ absorbance reading of sample extracts

\section{Results and Discussion}

Statistical Analysis of Total Phenolic content, Total Flavonoid content, Total Antioxidant capacity and Free radical scavenging activity of samples were carried out using Microsoft Excel 2007.

The total phenolic content of leaves of $E$. sphaericus and roots of P.zonale was calculated using from the Regression equation of calibration curve and expressed as gallic acid equivalents (GAE) per gram of the extract $\mathrm{mg} / \mathrm{g}$. The results are represented in fig $1 \& 2$. Our study showed that the total phenolic content in methanolic leaf extract of $E$. sphaericus was $37.5 \mathrm{mg} \mathrm{GAE} / \mathrm{g}$ of dry weight of the extract. Kumara et al., 2008 showed that the ethanolic leaf extract of E. sphaericus was found to be $56.79 \pm 1.6 \mathrm{mg} \mathrm{GAE} / \mathrm{g}$ of dry material. Another paper stated that total phenolic content in methanolic leaf extract of E. sphaericus showed high phenolic content $247.6+3.91 \mathrm{mg} \mathrm{GAE} / \mathrm{g}$ (Pandey et al.,2014). The considerable difference between results of phenolic content may be due to environmental related factors like temperature, climate, location, soil conditions and rainfall. It has been reported that rainfall has a considerable effect on phenolic content (Manach et al., 2004). The total phenolic content of root extract P.zonale $(24 \mathrm{mg} / \mathrm{GAE}$ in per gram of dry weight of extract) has not been analysed before and ours is the first study to do it.

Total flavonoid content of methanolic extracts was calculated from the regression equation of calibration curve and expressed as quercetin equivalents $(\mathrm{QE})$ per gram of the extract $\mathrm{mg} / \mathrm{g}$. The results are represented in fig $3 \& 4$.

The total flavonoid content in methanolic leaf extract of E. sphaericus showed high flavonoid content $61.9+2.83 \mathrm{mg} \mathrm{QE} / \mathrm{g}$ in study done by Pandey et al., 2014 as compare to the present study in which the total flavonid content of E. sphaericus was $53.3 \mathrm{mg} \mathrm{QE} / \mathrm{g}$ dry weight. Total phenolic content in ethanolic leaf extract of E. sphaericus was found to be $18.53 \pm 0.3 \mathrm{mg}$ Quercetin equivalents/g of dry material (Kumara et al., 2008). The total flavanoid content of root extract of $P$. zonale has not been analysed before. According to our study, the total flavonoid content of root extract of $P$. zonale was $21.05 \mathrm{mg} / \mathrm{QE}$ dry weight of the extract. It has been reported that flavonoid content is always higher in upper parts of the plants as compare to roots (J.S Kim ; 2016) and here it has been clearly shown that flavonoid content of roots of Pelargonium zonale is lower than leaf extract of E. sphaericus. 

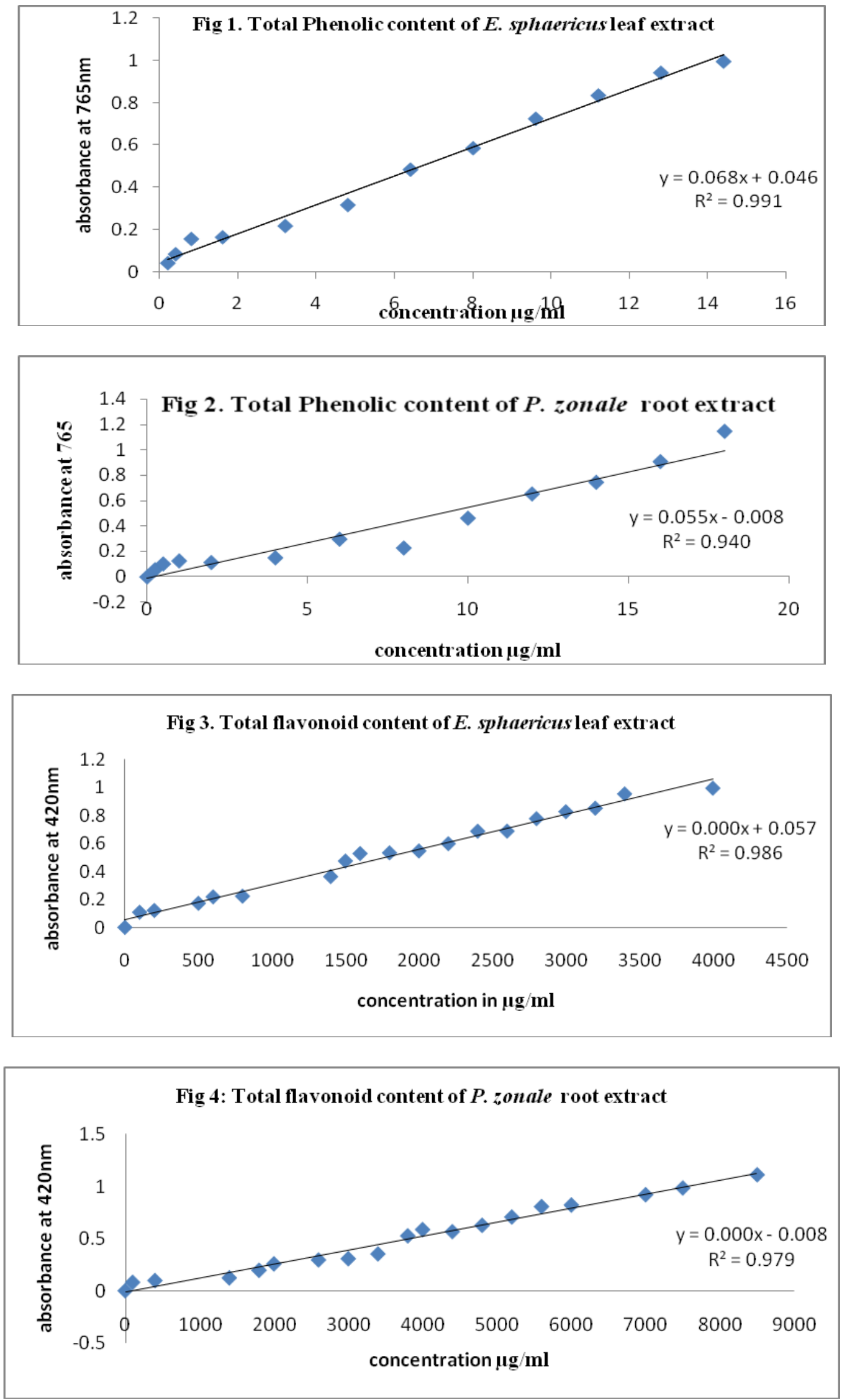

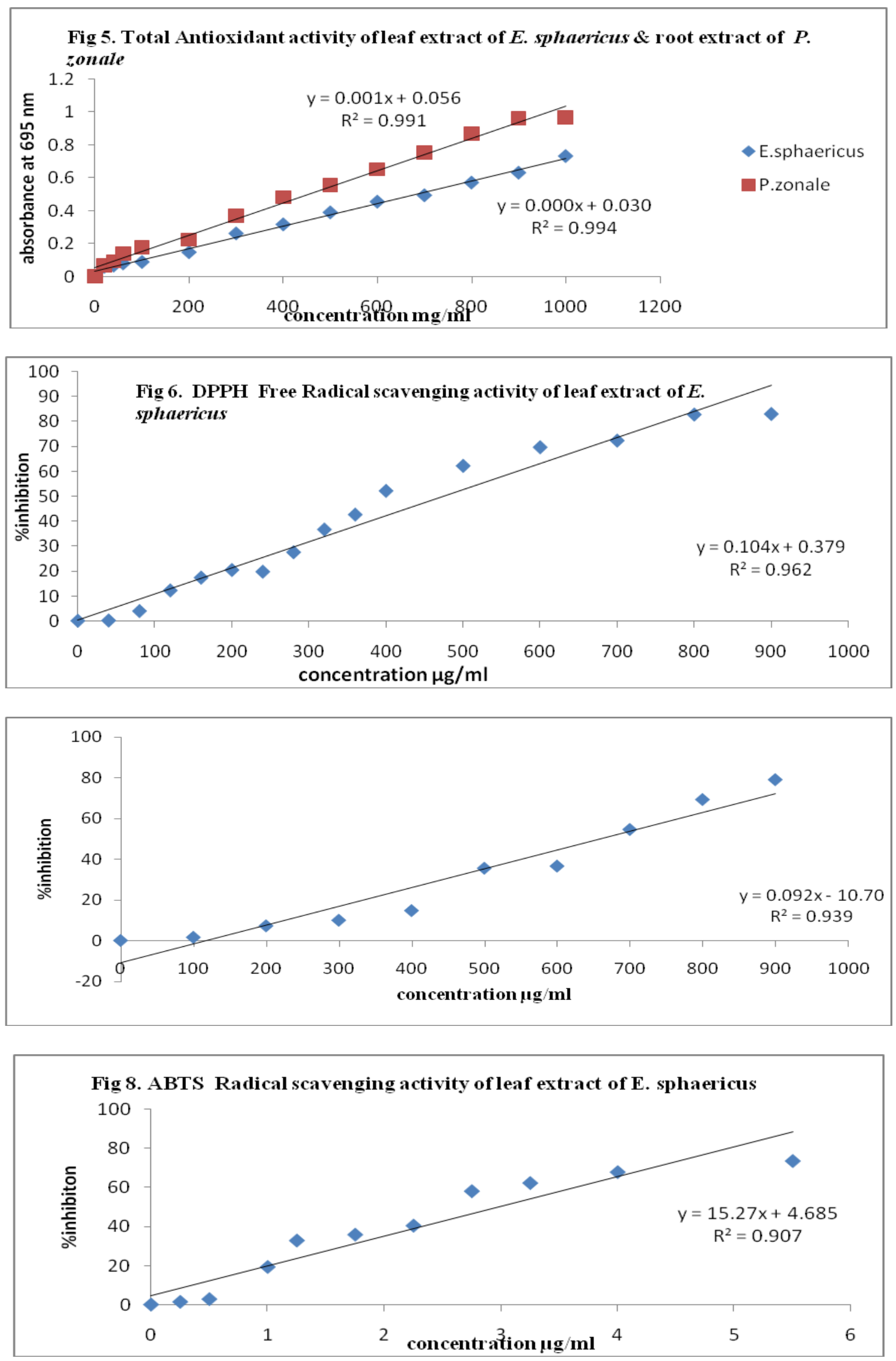


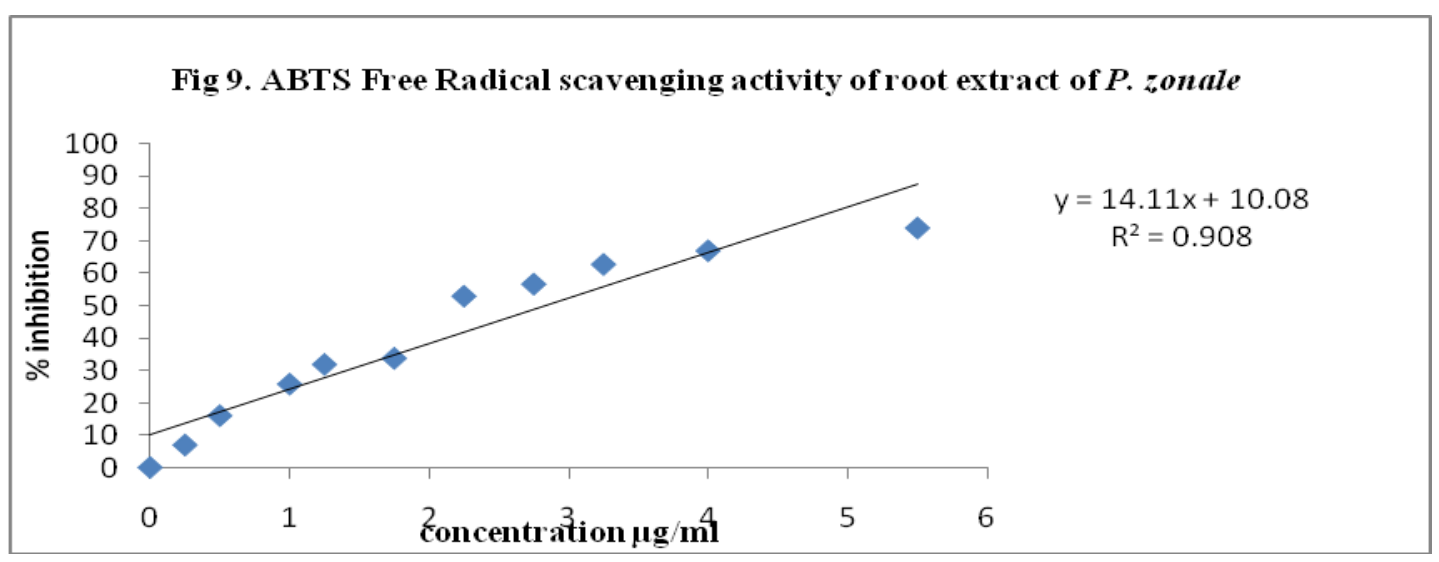

Our study showed the total antioxidant capacity of $P$. zonale was found to be $25.0 \mathrm{mg}$ ascorbic acid equivalents at $500 \mu \mathrm{g} / \mathrm{ml}$ extract concentration which is higher than $E$. sphaericus (14.28 $\mathrm{mg}$ ascorbic acid equivalents at $500 \mu \mathrm{g} / \mathrm{ml}$ extract). Total antioxidant capacity of E. sphaericus was found to be $24.18 \mathrm{mg}$ ascorbic acid equivalents at $500 \mu \mathrm{g} / \mathrm{ml}$ extract concentration (Kumar et al., 2008). This good antioxidant activity in $P$. zonale might be attributed to the presence of phytochemicals, such as flavonoids and biflavones. The results for total antioxidant activity are shown in fig 5.

DPPH assay is an important assay for the determination of free radical scavenging property of the plant extract and lower $\mathrm{IC}_{50}$ means good radical scavenging activity. In one study, DPPH radical scavenging activity was seen in $70 \%$ acetone extract of $E$. sphaericus and $\mathrm{IC}_{50} 34.00 \mu \mathrm{g} / \mathrm{ml}$ was observed (Pandey et al., 2014).Free radical scavenging activity of root extract $P$. zonale has not been analyzed before. Present study showed that $E$. sphaericus $\left(\mathrm{IC}_{50}\right.$ value $=$ $477.125 \mu \mathrm{g} / \mathrm{ml}$ ) has higher free radical scavenging activity as compare to $P$. zonale $\left(\mathrm{IC}_{50}\right.$ value $\left.=659.89 \mu \mathrm{g} / \mathrm{ml}\right)$. Thus present investigation shows that leaves of $E$. sphaericus have higher radical scavenging activity as compare to roots of $P$. zonale.

As per our study, shown in fig. 8, 9 both P.zonale $\left(\mathrm{IC}_{50}\right.$ value $\left.=2.82\right)$ and $E$. sphaericus $\left(\mathrm{IC}_{50}\right.$ value $\left.=2.96\right)$ has highest free radical scavenging activity as compare to BHT $\left(\left(\mathrm{IC}_{50}\right.\right.$ value $\left.=12.56\right)$. This point is very important as BHT is very commonly used as an antioxidant in food preservation and it is known to be harmful to the human health (Sharla et al., 2009).

Therefore, BHT can be replaced with these medicinal plants for their use in food and pharmaceutical industry. So there is great need to focus on natural or plant derived antioxidants. The free radical scavenging activity of roots of $P$. zonale gives a hope for investing our time and resources into further analysis of plant based antioxidants. Our results are novel as ABTS assay has not been performed on $P$. zonale root extract before this study.

The present study demonstrates that both medicinal plants possess good antioxidant capacity and free radical scavenging activity and provide information about antioxidant properties and polyphenolic content of selected Indian medicinal plants which could be used in pharmaceutical and food industry in place of synthetic antioxidants. The finding of this study supports the fact that $P$. zonale root extracts and E. sphaericus leaf extract can potentially be used as novel antioxidants in the food, cosmetic and pharmaceutical industries. 


\section{Acknowledgement}

Authors are thankful to the Department of Biotechnology, Panjab University, Chandigarh (India) for providing financial assistance and infrastructure to carry out research.

\section{References}

Barlow, S.M., 1990. Toxicological aspects of antioxidants used as food additives In: Food Antioxidants, Hudson BJF (Eds.) Elsevier, London. Pp. 253-307.

Battin, E., and Brumaghim, J.L. 2009. Antioxidant activity of sulfur and selenium: a review of reactive oxygen species scavenging, glutathione peroxidase, and metal-binding antioxidant mechanisms. Cell Biochem. Biophys. 55, 1-23.

Bedraj, P., and Meena, R. 2014. Estimation of Total Phenolic and Flavonoid Contents in Some Medicinal Plants and Their Antioxidant Activities. Nepal Journal of Science and Technology. 15 (1): 53-60.

Bettridge, D. J., 2000. What is Oxidative Stress? Metabolism. 49 (2): 3-8.

Bhatt, I. D., Rawat, S. and Rawal, R. S. 2000.Antioxidants in Medicinal Plants in: Biotechnology for Medicinal Plants (Eds.). Pp 295-326.

Branen, A. L., 1975. Toxicology and biochemistry of butylated hydroxyl anisol and butylated hydroxytoluene. Journal of American Oil Chemists Society. 5: 59- 63.

Carocho, M., and Ferreira, I. C. 2013. A review on antioxidants, prooxidants and related controversy: natural and synthetic compounds, screening and analysis methodologies and future perspectives. Food Chem. Toxicol. 21: $15-25$.

Chang, C. C., Yang, M. H, Wen, H. M. and Chern, J. C. 2002. Estimation of total flavonoid content in propolis by two complementary colorimetric methods. Journal of Food and Drug Analysis. 10: 178-182.

Demiray, S., Pinato, M. E. and Castro, P. M. L. 2009. Evaluation of phenolic profiles and antioxidant activities of Turkish medicinal plants: Tilia argentea, Crataegi folium leaves and Polygonum bistorta roots. International Journal of Pharmacological and Pharmaceutical Sciences. 3(6): 74-79.

Fang, Y. Z., Yang, S. and Wu. G. 2002. Free radicals, antioxidants, and nutrition. Nutrition. 18 (10): 872-879.

Kim, J.S., 2016. Investigation of Phenolic, Flavonoid, and Vitamin Contents in Different Parts of Korean Ginseng (Panax ginseng C.A. Meyer). Prev Nutr Food Sci. 21(3): 263-270.

Kumara, T.S, Shanmugama, S., Palvannanb, T. and Kumar, V. M. B. 2008 Evaluation of Antioxidant Properties of Elaeocarpus ganitrus Roxb. Leaves. Iranian Journal of Pharmaceutical Research. 7(3): 211-215.

Machlin, L. J. and Bendich, A.1987. Free radical tissue damage: protective role of antioxidant nutrients. FASEB J. 1(6): 441- 445.

Manach, C., Scalbert, A., Morand, C., Rémésy, C. and Jiménez. L. 2004. Polyphenols: food sources and bioavailability. Am J Clin Nutr. 79(5): 727-47.

Mativandlela, S. P. N, Lall, N. and Meyer, J. J. M. 2006. Antibacterial anti-fungal and antitubercular activity of Pelargonium reniforme (CURT) and Pelargonium sidoides (DC) (Geraniaceae) root extracts. South Afr. J. Bot.72: 232- 237.

Miguel, M. G., 2009. Antioxidant activity of medicinal and aromatic plants. Flavour and Fragrance Journal. 25(5): 291312. 
Prieto, P., Pineda, M. and Aquilar. M. 1999. Spectrophotometric quantitation of antioxidant capacity through the formation of a phosphomolybdenum complex: specific application to the determination of vitamin E. Anal Biochem. 269 (2): 337-41.

Re, R., Pellegrini, N. Proteggente, A. Pannala, A. Yang, M. and Rice-Evans C. 1999. Antioxidant activity applying an improved ABTS radical cation decolorization assay. Free Radic. Biol. Med. 26: 1231-123

Roja, G. and Rao, P. S. 2008. Anticancer compounds from tissue cultures of medicinal plant. Journal of Herbs, Spices and Medicinal Plants. 7(2): 71102.

Sharla, R., 2009. Antioxidants: The truth about BHA, BHT, TBHQ and other antioxidants used as food additives. Tigmor Book Publishers. Pp 1-48.

Siddhuraju, P. and Becker, K. 2003. Antioxidant properties of various solvent extracts of total phenolic constituents from three different agroclimatic origins of drumstick tree (Moringa oleifera Lam.) leaves. Journal of Agricultural and Food Chemistry. 51(8): 2144-2155.

Sies, H., 1991.Oxidative stress: From basic research to clinical application. The American Journal of Medicine. 91 (3): 31-38.

Surinrut, P., Kaewsutth, S. and Surakarnkul. R. 2005. Radical scavenging activity in fruit extracts. In: Proceedings of the WOCMAP III, Vol. 5: Quality, Efficacy, Safety, Processing and Trade in MAPs, E. Brovelli, S. Chansakaow, D. Farias et al., Eds., vol. 5, ISHS.

Yildirim A., Mavi, A. and Kara, A. A. 2001. Determination of antioxidant and antimicrobial activities of Rumex crispus L. extracts. Journal of Agricultural and Food Chemistry. 9: 4083-4089.

\section{How to cite this article:}

Ravi Deepika, Jagtar Singh and Naindeep Kaur. 2018. Comparison of Total Phenolic Content, Total Flavonoid Content, Antioxidant capacity and Free Radical Scavenging Activity of Leaves of Elaeocarpus sphaericus and Roots of Pelargonium zonale. Int.J.Curr.Microbiol.App.Sci. 7(02): 2846-2854. doi: https://doi.org/10.20546/ijcmas.2018.702.347 